\title{
A Study on the Construction of Finance Management Information System under the Environment of ERP
}

\author{
Wu Yan \\ Jilin Business and Technology College, \\ Changchun City JilinProvince,China \\ Email;wuyan20050305@163.com
}

\begin{abstract}
ERP is a brandnew modern management means, while Finance Management Information System (FMIS) is the important part of ERP. To establish and improve FMIS is not only the significant means of realizing modernization of finance management, but is also the essential measures of perfection of ERP. Based on summing up the process of the development of FMIS, this article designs the Finance Managenment Information System which can realize the function of financial accounting and management accounting.
\end{abstract}

Key words- ERP; Finance Management; Information System; Construction

\section{INTRODUCTION}

ERP is the abbreviation of Enterprise Resource Planning; it is a relatively popular word in business management circle. While ERP is not a new concept, ERP refers to the enterprise management system that integrates the internal resource of the enterprise, making the business data unifiction and completely online processing. From the perspective of technology level, it uses the information technology achievements to plan, arrange and integrate the interal resource of the enterprises, including human resource, finance and material assets, thus conveninence is achieved, productivity is increased, and competitiveness of the enterprise is enhanced. From the angle of management level, it is a realtive complete integrated management information system, including these management systems, such as distribution, manufanture, accounting, quality control, after-sale service, human resource, material and so on. ${ }^{[1]}$ In the respect of electronic commerce operation system, ERP is the foundation work. The information management of the enterprise will lose the support without ERP, and the quaity of whole electronic commerce will reduce. Therefore, as a new means of modern manegement, its core management theory is to realize the effective integration and management of information resource in all aspects of operation and management of business.

\section{THE DEVELOPMENT OF FMIS}

ERP develops along with the times. So does the FMIS. From computerized accounting that cannot be called information system at the very beginning to independent financial software, then to the integrated finance management information system, FMIS is constantly improving with the creativity of information technology and management theory. Its development process can be seen in Fig. 1.

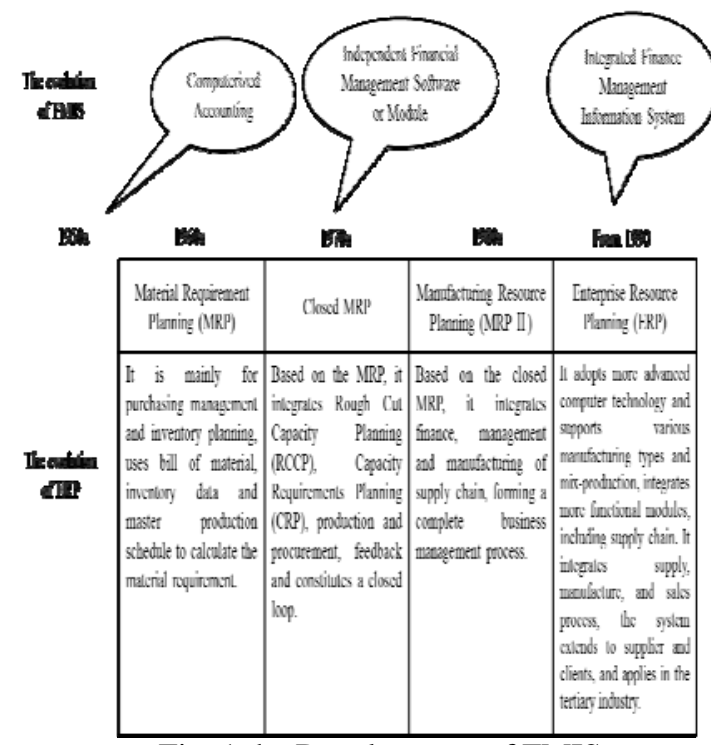

Fig. 1 the Development of FMIS

With computer, data transmission and communication equipment as the core of data processing system, the initial computerized accounting accomplished a series of accounting activities, such as original data collection, archiving, verification, classification, registration, computation, summarization and reporting. ${ }^{[2]}$ During this process, accountants only need to do some auxiliary manipulation, i.e., accountants need to input the data into the processing system according to the specified requirements, and then the computer will accomplish accounting data processing automatically according to the pre-programmed programs, and the final results - financial report will be printed.

With the emergence of new computer technologies and management thoughts, accounting computerization develops into single financial software. This stage of the financial software is basically run in DOS operating platform, it just completed an independent financial processing work functionally. Then accounting financial software based on LAN (Local Area Network) appeared. In this phase, the financial software applications range from single mode to small local area network that has certain data sharing ability. ${ }^{[3]}$

From the mid-to-late 1990s, the enterprise started to reconstruct organization structure and management mode, which is known as Business Process Reengineering (BPR). On the other hand, enterprises attach importance to advanced information technology. Based on MRP, ERP 
system was implemented in order to support the new supply chain and strategic decision effectively. ${ }^{[4]} \mathrm{By}$ that time, the financial software became managerial financial software. In this stage, the financial software adopts C/S (client/server) calculation mode, concerning enterprise management content, such as financial analysis, financial forecast, financial control and so on.

With the increasing popularity of the Internet and the development of electronic commerce, higher requirements are imposed on financial management system by the enterprise. A new generation of financial software is based on Internet B/S (browser/server) calculation mode, using Web technology, multimedia technology and Internet management software, in accordance with the strategy that business mode of operation develops to the electronic commerce. $^{[5]}$ It is the mainstream trend of international financial management software technology development.

Now intelligent analysis financial management system is important development direction of financial management software. Based on the existing financial management system, the financial management system that can conduct financial analysis automatically will be developed continually. Its main function is to support the application of database and to realize the intelligent data mining analysis of OLAP, and also to provide more detailed financial statements and support the financial situation, profit and loss and the structure of cash flow analysis, comparative analysis and trend analysis and other major financial indicators analysis.

It can be seen that after the 90s, the core of the financial management system was transferred from accounting to financial management, which has strengthened the management function and provided intelligent financial analysis supported by financial information for management decision. The business' impact and control on finance has been stressed, and the system also developed from the independent, closed system to fully integrating into the whole enterprise management, realizing the integration with other management systems, and new management idea, management technology, IT technology. At the same time, higher requests are made for financial executives of the enterprise. ${ }^{[6]}$ It demands that accountants should be equipped with advanced management concept, and should have the ability to integrate professional financial knowledge with the latest management concept, so as to adapt to the development of the enterprise, enhance market competitiveness of the enterprise, and comply with the requirements of the knowledge economy era.

\section{III.THE STRUCTURE DESIGN OF FMIS UNDER THE ENVIRONMENT OF ERP}

Finance Management Information System is an integral part of ERP. To establish and perfect FMIS is a significant means to realize the modernization of financial management, and is also the important measure to improve ERP. At present, there is still no independent structure system of FMIS in most domestic enterprises. Practically, they just stay in the stage of the simple application of financial software, while many developed countries have focused on the development of FMIS. Thus, grasping the development direction and trend of FMIS and establishing a comprehensive and efficient FMIS is imminent.

There is no authoritative definition for FMIS under the environment of ERP. According to CCID Consulting, the integrated FMIS "can help the enterprise to process all kinds of financial data and to analyze, manage and supervise financial activities. ${ }^{[7]}$ It also can help to communicate with the investor. Through the integration of all kinds of financial information, it can help the enterprise to carry out the global control and make all kinds of strategic decision of enterprise management stratum based on accurate and real-time basis,... is the core part of enterprise management information system ." Its structure is shown in Fig.2.

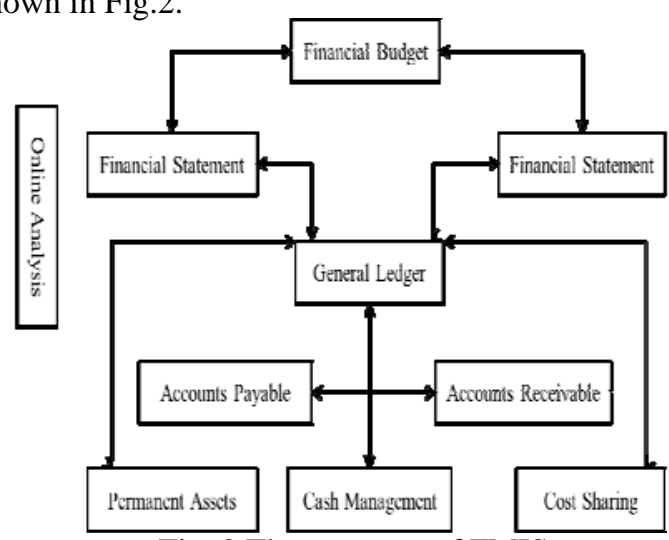

Fig. 2 The structure of FMIS

FMIS under the environment of ERP is composed of modules; each module realizes different functions, including financial accounting and management accounting: A. Financial Budget

It is used to record budget and plan, and it also conducts real-time budget, plan and the actual business operation, comparative analysis. ${ }^{[8]}$ So the enterprise management stratums are able to adjust the budget, plan and business strategy according to the results of the analysis timely.

\section{B. Statement Analysis}

It integrates the data of all business systems, and when each transaction occurs or changes, the relevant data will be integrated into the financial system, and will be transferred to the report system of financial system in real-time, finally will be reflected in the statements.

\section{General Ledger Module}

It is the venue of financial management system. It is used to define general ledger, subsidiary ledger structure, and set general ledger accounting subject and subsidiary ledger account according to the framework. It is also used for the classification of accounting period, setting accounting calendar, dealing with the day-to-day accounting.

\section{Accounts Receivable, Accounts Payable Module}

It is completely for business process, it manages system through controlling the highly integrated supply chain of subject setting. It can handle many currencies, tax rates, and a variety of money payment business.

E. Cost Management Module 
It adopts standard cost system of ERP system; the system can automatically calculate the standard cost and actual cost. And the discrepancy will be automatically carried out so as to facilitate enterprise to find the source of difference and the remedy to the case, and further to help enterprises to optimize the process of cost control.

\section{F. $\quad$ Cash Management Module}

The issues centered on production, development and profit and many other aspects are related to fund management, and efficient capital management forms the core competitiveness of the enterprise.

\section{G. $\quad$ Cost Allocation Module}

It supports the method that the period cost is allocated by labor hour or machine hour. The cost can be allocated to each person or machine of each workshop, so that the cost management is broken down to the most basic units.

\section{H. Online Analysis Module}

It uses online analysis module. All the staff of the enterprise and external relevant personnel in the premise of being authorized can conduct modeling analysis of the financial data. ${ }^{[9]}$ On-Line Analytical Processing can be used in more sophisticated financial analysis for a variety of data modeling. For example, sales data can be compared according to the area, product type and the sales staff, and various factors that influence the sales, such as price, can be analyzed by sensitivity modeling analysis, thus the scientific decision will be obtained.

\section{REFERENCES}

[1] Yuqing Zhou, Boying Liu. "ERP and Enterprise Management 15-17

[2] Zhaona. "An Analysis on the Reform of Financial Control under the Environment of ERP”[J]. 《Financial Accounting Theory》2005(4). Page 45

[3] Longming, Xiaohong Yang. "A Research on the Enterprise Finance Management System”[J] Journal of Xianning College. 2006(6). Page 36

[4] Changying Zhou. "On the Construction and Application of ERP in the Enterprise” [J]. Contemporary Economics. 2012(12). Page 29

[5] Zhangjie. "A Study on the Function of Finance Management Information System under the Environment of ERP”[D]. Southwestern University of Finance and Economics 2008. Page 21-23

[6] Yunfeng Ma, Chunhua Sun. "The Application of Finance Management System in the Forestry Enterprise Based on the Environment of ERP'[J]. Green Finance and Accounting. 2009(03) Page 68

[7] Songning. “A Discussion of the Finance Management Information System of the Enterprise in Present China”[J]. Modern Business. 2011(18). Page 45

[8] Yongchao Wang. "On the Function and Significance of Finance Management Information System in the Modernization of Enterprise Management”[J]. Modern Business. 2011(05) Page 44

[9] Jinwei. "Research and Analysis of Enterprise Finance Management Information System”[J]. Knowledge Economy. 2011(18), Page 56 